MONEY ILLUSION IN THE STOCK MARKET:

\title{
THE MODIGLIANI-COHN HYPOTHESIS
}

Randolph B. Cohen

Christopher Polk

Tuomo Vuolteenaho

Working Paper 11018 
NBER WORKING PAPER SERIES

\title{
MONEY ILLUSION IN THE STOCK MARKET: THE MODIGLIANI-COHN HYPOTHESIS
}

\author{
Randolph B. Cohen \\ Christopher Polk \\ Tuomo Vuolteenaho \\ Working Paper 11018 \\ http://www.nber.org/papers/w11018
NATIONAL BUREAU OF ECONOMIC RESEARCH
1050 Massachusetts Avenue
Cambridge, MA 02138
January 2005

An earlier draft of the paper was circulated under the title "How inflation illusion killed the CAPM." We would like to thank Cli. Asness, John Campbell, Ed Glaeser, Jussi Keppo, Stefan Nagel, Andrei Shleifer, Jeremy Stein, and three anonymous referees for helpful comments. The views expressed herein are those of the author(s) and do not necessarily reflect the views of the National Bureau of Economic Research.

(C) 2005 by Randolph B. Cohen, Christopher Polk, and Tuomo Vuolteenaho. All rights reserved. Short sections of text, not to exceed two paragraphs, may be quoted without explicit permission provided that full credit, including (C) notice, is given to the source. 
Money Illusion in the Stock Market: The Modigliani-Cohn Hypothesis

Randolph B. Cohen, Christopher Polk, and Tuomo Vuolteenaho

NBER Working Paper No. 11018

December 2004

JEL No. G12, G14, N22

\begin{abstract}
$\underline{\text { ABSTRACT }}$
Modigliani and Cohn [1979] hypothesize that the stock market suffers from money illusion, discounting real cash flows at nominal discount rates. While previous research has focused on the pricing of the aggregate stock market relative to Treasury bills, the money-illusion hypothesis also has implications for the pricing of risky stocks relative to safe stocks. Simultaneously examining the pricing of Treasury bills, safe stocks, and risky stocks allows us to distinguish money illusion from any change in the attitudes of investors towards risk. Our empirical resuts support the hypothesis that the stock market suffers from money illusion.

Randolph B. Cohen

Harvard Business School

rcohen@hbs.edu

Christopher Polk

Northwestern University

c-polk@kellogg.northwestern.edu

Tuomo Vuolteenaho

Harvard University

Department of Economics

Littauer Center

Cambridge, MA 02139

and NBER

t_vuolteenaho@harvard.edu
\end{abstract}




\section{Introduction}

Do people suffer from money illusion, confusing nominal dollar values with real purchasing power? When the difference between real and nominal quantities is small and stakes are relatively low, equating the nominal dollar amounts with real values provides a convenient and effective rule of thumb. Therefore, it seems plausible that people often ignore the rate of inflation in processing information for relatively small decisions. ${ }^{1}$

Modigliani and Cohn [1979] hypothesize that stock-market investors may also suffer from a particular form of money illusion, incorrectly discounting real cash flows with nominal discount rates. An implication of such an error is that time-variation in the level of inflation causes the market's subjective expectation of the future equity premium to deviate systematically from the rational expectation. Thus when inflation is high (low), the rational equity-premium expectation is higher (lower) than the market's subjective expectation, and the stock market is undervalued (overvalued). The claim that stock market investors suffer from money illusion is a particularly intriguing and controversial proposition, as the stakes in the stock market are obviously very high.

Nevertheles, recent time-series evidence suggests that the stock market does suffer from money illusion of Modigliani and Cohn's variety. Sharpe [2002] and Asness [2000] find that stock dividend and earnings yields are highly correlated with nominal bond yields. Since stocks are claims to cash flows from real capital and inflation is the main driver of nominal interest rates, this correlation makes little sense, a point made recently by Ritter and Warr [2002], Asness [2003], and Campbell and Vuolteenaho [2004]. These aggregate studies suffer from one serious weakness, however. Inflation may be correlated with investors' attitudes towards risk, which directly influence stock prices even if investors do not suffer from money illusion. To the extent these

\footnotetext{
${ }^{1}$ The term "money illusion" was coined by John Maynard Keynes early in the 20th Century. In 1928, Irving Fisher gave the subject a thorough treatment in his book "The Money Illusion." Since then numerous papers have described implications of money illusion to test for its existence. The most widely discussed of these implications is stickiness in wages and prices (see Gordon 1983 for a review of the evidence on this topic). Although money illusion can exist even in the absence of inflation, inflation is central to most money illusion stories. Fisher and Modigliani (1978) catalog the ways in which inflation could affect the real economy, with money illusion as one important source of real effects. Shafir, Diamond and Tversky (1997) examine in detail potential effects of money illusion and present evidence on these effects along with a theory of the psychological underpinnings of the illusion.
} 
aggregate studies fail to fully control for risk, the results may confound the impact of risk attitudes and money illusion.

Our novel tests explore the cross-sectional asset-pricing implications of the ModiglianiCohn money-illusion hypothesis. Simultaneously examining the pricing of Treasury bills, safe stocks, and risky stocks allows us to distinguish money illusion from changing attitudes of investors towards risk. The key insight underlying our tests is that money illusion will have a symmetric effect on all stocks' yields, regardless of their exposure to systematic risk. In contrast, the impact of investor risk attitudes on a stock's yield will be proportional to the stock's risk, as risky stocks' yields will be affected much more than safe stocks' yields will be. This insight allows us to cleanly separate the two competing effects.

Specifically, we assume that investors use the logic of the Sharpe-Lintner capital asset pricing model [CAPM, Sharpe 1964, Lintner 1965] to measure the riskiness of a stock and to determine its required risk premium. According to the CAPM, a stock's beta with the market is its sole relevant risk measure. In the absence of money illusion (and other investor irrationalities), the Sharpe-Lintner CAPM predicts that the risk compensation for one unit of beta among stocks, which is also called the slope of the security market line, is always equal to the rationally expected premium of the market portfolio of stocks over short-term bills. For example, if a risky stock has a beta of 1.5 and the rationally expected equity premium is 4 percent, then that stock should have a rationally expected return of the Treasury-bill yield plus 6 percent. Conversely, a safe stock with a beta of 0.5 should only earn a 2 percent premium over Treasury bills, and the risky stock will therefore return a premium of 4 percent over the safe stock.

The joint hypothesis of money illusion and the CAPM offers a sharp, quantitative prediction. We show that money illusion implies that, when inflation is low or negative, the compensation for one unit of beta among stocks is larger (and the security market line steeper) than the rationally expected equity premium. Conversely, when inflation is high, the compensation for one unit of beta among stocks is lower (and the security market line shallower) than what the overall pricing of stocks relative to bills would suggest. In our above example, suppose that high inflation leads moneyillusioned investors, who expect a 4 percent equity premium, to undervalue the stock market so that the rational expectation of the equity premium is 7 percent. Then these investors will price the risky stock to yield only a 4 percent return premium over the safe stock. Consequently, when inflation is high, the average realized equity 
premium ( 7 percent) will be higher than the average return premium of the risky stock over the safe stock (4 percent).

Our empirical tests support this hypothesis. First, as an illustration, we sort the months in our 1927-2001 sample into quartiles based on lagged inflation and examine the pricing of beta-sorted portfolios in these quartiles. The slope of the solid line in Figure 1 denotes the price of risk implied by the pricing of the overall stock market relative to that of short-term bills, i.e, the equity premium that a rational investor should have expected. The dashed line is the security market line, the slope of which is the price of risk implied by the pricing of high-risk stocks relative to that of low-risk stocks. As predicted by the money-illusion hypothesis, the figure shows that during months that are preceded by inflation in the lowest quartile of our sample, the relation between average returns and CAPM betas is steeper than the slope predicted by the Sharpe-Lintner CAPM and no money illusion. Conversely, during months that are preceded by inflation in the highest quartile of our sample, the security market line estimated from the cross-section of beta-sorted portfolios is much shallower than the expected equity premium.

Second, we introduce a new method for estimating the excess slope and excess intercept of the security market line among stocks, relative to the predictions of the Sharpe-Lintner CAPM. Our statistical test combines Fama-MacBeth [1973] crosssectional and Black-Jensen-Scholes [1972] time-series regressions to solve for the excess slope and excess intercept as a function of the betas and conditional alphas from the time-series regression's parameters. The idea behind this statistical test is exactly the same as the one illustrated in Figure 1, but allows for a convenient and powerful statistical hypothesis test. Our tests indicate that the excess intercept of the security market line comoves positively and the excess slope negatively with inflation, as predicted by the Modigliani-Cohn money-illusion hypothesis.

At first, it may seem incredible that stock-market investors, with trillions of dollars at stake, make such a pedestrian mistake. Fortunately, or perhaps unfortunately, we need not look any further than to the leading practitioner model of equity valuation, the so-called "Fed model ${ }^{2}$," to find corroborating evidence of stock-market investors falling prey to money illusion. The Fed model relates the yield on stocks to the yield on nominal bonds. Practitioners argue that the bond yield plus a risk premium defines a "normal" yield on stocks, and that the actual stock yield tends to revert

\footnotetext{
${ }^{2}$ Despite this name, the model has absolutely no official or special status within the Federal Reserve system.
} 
to this normal yield. Consistent with this practitioner argument, Sharpe [2002], Asness [2000], and Campbell and Vuolteenaho [2004] find that the Fed model is quite successful as an empirical description of aggregate stock prices - prices are set as if the market used the Fed model to price stocks. Logically, however, the Fed model is on weak grounds, as it is based on precisely the money-illusion error noted by Modigliani and Cohn.

Even if most stock-market investors confuse nominal and real quantities, could a small number of wealthy and rational arbitrageurs still eliminate any potential mispricing? We believe that rational arbitrageurs would be very conservative in accomodating supply and demand due to money illusion. The Sharpe ratio (the expected excess return divided by the standard deviation of excess return) of a bet against the money-illusion crowd is likely to be relatively low, because one can only make a single bet at a time and because the mispricing may be corrected very slowly. This potential slow correction of mispricing is a particularly important limiting factor of arbitrage, as any attempt to correct the inflation-related mispricing exposes the arbitrageur to the uncertain development of the stock market's fundamentals. Mispricing that corrects slowly necessarily requires long holding periods for arbitrage positions along with significant exposure to volatility, as the variance of fundamental risk grows linearly in time. In fact, had a rational arbitrageur bet against money illusion by buying stocks on margin in the early 1970's, his profits would have been negative for more than a decade. As Modigliani and Cohn noted in 1977: "On the other hand, those experts of rational valuation who could correctly assess the extent of the undervaluation of equities, had they acted on their assessment in the hope of acquiring riches, would have more than likely ended up with substantial losses." In summary, mispricing caused by money illusion has precisely those characteristics that Shleifer and Vishny (1997) suggest effectively prevent arbitrage activity.

\section{Money illusion and its implications}

\subsection{Modigliani and Cohn's [1979] money-illusion hypothesis}

The correct application of the present-value formula discounts nominal cash flows at nominal discount rates or real cash flows at real discount rates. Modigliani and Cohn [1979] propose that stock-market investors, but not bond-market investors, suffer from 
money illusion, effectively discounting real cash flows at nominal rates.

What mechanism could cause the bond market to correctly reflect inflation, while the stock market suffers from money illusion? According to the Modigliani-Cohn hypothesis, money illusion is due to the difficulty of estimating long-term future growth rates of cash flows. Consider an investor who thinks in nominal terms. Since nominal bonds have cash flows that are constant in those terms, estimating a growth rate for bonds is not difficult. In contrast, the task of estimating the long-term expected cash-flow growth for stocks is far from trivial.

For example, suppose that this investor erroneously assumes that long-term earnings and dividend growth are constant in nominal terms, and uses all past historical data to estimate a long-term growth rate for a stock. Of course a more reasonable assumption would be that expected long-term growth is constant in real terms. If expected long-term growth is constant in real terms, yet the investor expects it to be constant in nominal terms, then in equilibrium stocks will be undervalued when inflation is high and overvalued when inflation is low.

The basic intuition of the Modigliani-Cohn hypothesis can easily be captured by examining a money-illusioned investors approach to stock valuation. Consider the classic "Gordon growth model" [Williams 1938, Gordon 1962] that equates the dividend-price ratio with the difference between the discount rate and expected growth:

$$
\frac{D_{t}}{P_{t-1}}=R-G
$$

where $R$ is the long-term discount rate and $G$ is the long-term growth rate of dividends. $R$ and $G$ can either both be in nominal terms or both in real terms, but the Gordon growth model does not allow mixing and matching nominal and real variables. If the expected returns are constant, the discount rate is exactly equal to the expected return on the asset. If conditional expected returns vary over time, however, the discount rate is only approximately equal to the long-horizon expected holding period return on the asset.

The Gordon growth model can also be thought of in terms of the investor's firstorder condition. If an investor is at the optimum portfolio allocation, then the discount rate or expected return $R$ on stocks must equal the yield on bonds plus a premium due to the higher covariance of stock returns with the investor's consumption. If an otherwise optimizing investor suffers from money illusion of Modigliani and Cohn's variety, then he thinks of $R$ in nominal terms and expects $G$ to be con- 
stant in nominal terms. If the inflation is time varying, however, the assumption of constant nominal $G$ doesn't make any sense, as it would imply a wildly variable real $G$. In real terms, there is no obvious reason why either $R$ or $G$ should change mechanically with expected inflation, if the consumer is rational. ${ }^{3}$

If stock-market investors suffer from money illusion and expect constant long-term growth in nominal terms, what will happen when inflation rises? Higher nominal interest rates resulting from inflation are then used by stock market participants to discount unchanged expectations of future nominal dividends. The dividend-price ratio moves with the nominal bond yield because stock market investors irrationally fail to adjust the nominal growth rate $G$ to match the nominal discount rate $R$. From the perspective of a rational investor, stock are thus undervalued when inflation is high and overvalued when inflation is low. A single small rational investor, facing a market populated by money-illusioned investors, would then tilt his portfolio towards stocks when inflation is high and away from stocks when inflation is low, so that the equilibrium risk premium of stocks would be justified by stock returns' covariance with his consumption.

To adapt the notation to conform with our subsequent empirical tests, first subtract the riskless interest rate from both the discount rate and the growth rate of dividends. We define the excess discount rate as $R^{e} \equiv R-R_{f}$ and the excess dividend growth rate as $G^{e} \equiv G-R_{f}$, where all quantities should again be either nominal or real. As we are considering the possibility that some investors are irrational, we follow Campbell and Vuolteenaho [2004] and distinguish between the subjective expectations of irrational investors (superscript $S U B J$ ) and the objective expectations of rational investors (superscript $O B J$ ).

As long as irrational investors simply use the present value formula with an erroneous expected growth rate or discount rate, both sets of expectations must obey the Gordon growth model:

$$
\begin{aligned}
\frac{D}{P} & =R^{e, O B J}-G^{e, O B J}=R^{e, S U B J}-G^{e, S U B J} \\
& =-G^{e, O B J}+R^{e, S U B J}+\left(G^{e, O B J}-G^{e, S U B J}\right) .
\end{aligned}
$$

In words, the dividend yield has three components: (1) the negative of objectively

\footnotetext{
${ }^{3}$ Some business-cycle dynamic (such as Fama's [1981] proxy hypothesis) might create a correlation of near-term discount rates and/or growth rates with inflation; however, such movements are a priori unlikely to move long-term discount rates and/or growth rates much.
} 
expected excess dividend growth, (2) the subjective risk premium expected by irrational investors, and (3) a mispricing term due to a divergence between the objective (i.e, rational) and subjective (i.e, irrational) growth forecast, $\varepsilon \equiv G^{e, O B J}-G^{e, S U B J}$. Notice that mispricing, $\varepsilon$, is specified in terms of excess yield, with $\varepsilon<0$ indicating overpricing and $\varepsilon>0$ underpricing. Notice also that the Gordon growth model requires that the expectational error in long-term growth rates, $G^{e, O B J}-G^{e, S U B J}$, be equal to the expectational error in long-term expected returns, $R^{e, O B J}-R^{e, S U B J}$.

Campbell and Vuolteenaho [2004] formalize the Modigliani-Cohn money-illusion story by specifying that mispricing or expectational error is a linear function of past smoothed inflation:

$$
\varepsilon \equiv G^{e, O B J}-G^{e, S U B J}=R^{e, O B J}-R^{e, S U B J}=\gamma_{0}+\gamma_{1} \pi,
$$

where $\pi$ is the expected inflation and $\gamma_{1}>0$. If one takes the Modigliani-Cohn hypothesis literally, one could argue that $\gamma_{1}=1$, i.e., inflation is (irrationally) fully priced into stock yields. The case in which $\gamma_{1}=1$ is consistent with the simple form of money illusion in which investors assume that the future expected cash-flow growth is constant in nominal terms.

\subsection{Cross-sectional implications of the money illusion}

While previous research has tested the aggregate time-series predictions of the ModiglianiCohn money-illusion hypothesis, the cross-sectional implications of this hypothesis have been largely unexplored in either the literature on behavioral finance theory or the empirical literature in general. (The main exception is Ritter and Warr's 2002 study, which examines the differential impact of inflation on a firm's stock price as a function of its financial leverage.) We fill this gap in the literature by developing and testing cross-sectional predictions resulting from the original Modigliani-Cohn hypothesis.

We base our cross-sectional predictions on three substantive assumptions. First, we assume that the market suffers from money illusion of the type described by equation (3). Second, we assume that the market makes no other type of systematic mistake in valuing stocks. Together, these two assumptions imply that equation (3) holds not only for the market but also for each individual stock:

$$
\varepsilon_{i} \equiv G_{i}^{e, O B J}-G_{i}^{e, S U B J}=R_{i}^{e, O B J}-R_{i}^{e, S U B J}=\gamma_{0}+\gamma_{1} \pi .
$$


An important result of these assumptions is that money-illusion's influence on mispricing is equal across stocks, i.e., $\varepsilon_{i} \equiv \varepsilon_{M}=\gamma_{0}+\gamma_{1} \pi$.

Our final assumption is that investors behave according to modern portfolio theory in evaluating risks, that is, they use the Sharpe-Lintner CAPM to set require risk premia. This implies that the slope of the relation between the subjective return expectation on an asset and that asset's CAPM beta is equal to the subjective market premium:

$$
R_{i}^{e, S U B J}=\beta_{i} R_{M}^{e, S U B J}
$$

This is in contrast with the usual, rational-expectations specification of the CAPM: $R_{i}^{e, O B J}=\beta_{i} R_{M}^{e, O B J}$. Note that we implicitly assume that betas are known constants so that subjective and objective expectations of betas are thus equal.

These assumptions allow us to derive the cross-sectional implication of the ModiglianiCohn [1979] money-illusion hypothesis. Substituting the subjective Sharpe-Lintner CAPM into (4) yields:

$$
\varepsilon_{i}=R_{i}^{e, O B J}-\beta_{i} R_{M}^{e, S U B J}
$$

Recognizing that market mispricing, $\varepsilon_{M}$, equals the wedge between objective and subjective market premia results in

$$
\begin{aligned}
\varepsilon_{i} & =R_{i}^{e, O B J}-\beta_{i}\left[R_{M}^{e, O B J}-\varepsilon_{M}\right] \Longleftrightarrow \\
\alpha_{i}^{O B J} & \equiv R_{i}^{e, O B J}-\beta_{i} R_{M}^{e, O B J}=\varepsilon_{i}-\beta_{i} \varepsilon_{M} .
\end{aligned}
$$

Above, $\alpha_{i}^{O B J}$ is an objective measure of relative mispricing, called Jensen's [1968] alpha in the finance literature. Since mispricing for both the market and stock $i$ is equal to the same linear function of expected inflation, $\gamma_{0}+\gamma_{1} \pi$, we can write

$$
\alpha_{i}^{O B J}=\gamma_{0}+\gamma_{1} \pi-\beta_{i}\left(\gamma_{0}+\gamma_{1} \pi\right)
$$

Equation (8) predicts that the (conditional) Jensen's alpha of a stock is a linear function of inflation, the stock's beta, and the interaction between inflation and the stock's beta. If the market suffers from money illusion, then when inflation is high a rational investor would perceive a positive alpha for low-beta stocks and negative alpha for high-beta stocks. Conversely, when inflation is low (or negative), a rational expectation of a stock's alpha is negative for low-beta stocks and positive for high-beta stocks. 
Recall that the security market line is the linear relation between a stock's average return and its beta. Equivalently, equation (8) states that both the intercept and the slope of the observed security market line deviate systematically from the rational-expectation Sharpe-Lintner CAPM's prediction. Moreover, this deviation is a function of inflation. Define the excess slope of the security market line as the cross-sectional slope of (objective) alpha on beta. Define the excess intercept of the security market line as the (objective) alpha of a unit-investment stock portfolio that has a zero beta. Equation (8) predicts that the excess intercept of the security market line equals $\gamma_{0}+\gamma_{1} \pi$ and the excess slope equals $-\left(\gamma_{0}+\gamma_{1} \pi\right)$ under the joint hypothesis of money illusion and the Sharpe-Lintner CAPM.

The above reasoning assumes that prices are exclusively set by investors who suffer from money illusion. What happens if some investors suffer from money illusion while other investors do not, and the two groups interact in the market? In the Appendix, we describe a very stylized equilibrium model, in which a fraction of the risk-bearing capacity in the market suffers from money illusion. This stylized model gives an intuitive prediction: The excess slope of the security market line is determined by the product of inflation and the fraction of the market's risk-bearing capacity controlled by money-illusioned investors.

The above hypotheses tie in closely with recent research on equity-premium predictability and inflation. A paper by Polk, Thompson, and Vuolteenaho (2004) assumes that the CAPM holds in terms of investors' subjective expectations, and uses the relative prices of high and low beta stocks to derive an estimate of the subjective equity premium. Polk, Thompson, and Vuolteenaho find that this estimate correlates well with proxies for the objective equity premium such as the dividend yield, and also has predictive power for the future equity premium. The major exception to their finding occurs in the early 1980's, when their subjective equity premium measure is low but the dividend yield, as well as the subsequent aggregate stock market return are both high. It is noteworthy that this period was also the peak of U.S. inflation.

Campbell and Vuolteenaho (2002) assume the validity of Polk, Thompson, and Vuolteenaho's (2004) measure of the subjective equity premium. Campbell and Vuolteenaho combine this measure with the Gordon growth model for the aggregate market to estimate the subjectively expected growth rate of aggregate cash flows. It appears that inflation drives a wedge between the subjective and objective estimates of aggregate growth, just as predicted by the Modigliani-Cohn hypothesis. 
In contrast, we essentially circle back to ask how money illusion affects the objective validity of the CAPM. Even if investors subjectively use the CAPM, does the CAPM describe the pattern of objective returns in the cross-section? The answer is that there should be an objective security market line, but it can be steeper or flatter than the prediction of the Sharpe-Lintner CAPM, i.e., the rational expectation of the equity premium.

\section{$3 \quad$ Empirical methodology and results}

Our main tests examine time variation in the excess intercept and slope of the security market line, and the relation of this time variation to inflation. Our estimation strategy is the following. First, we construct dynamic stock portfolios that are likely to show a large and consistent cross-sectional spread in their CAPM betas. The natural way to construct such portfolios is to sort stocks into portfolios each month on their past estimated stock-level betas. We record the returns on these value-weight portfolios, which become our basis assets.

Specifically, we generate our basis asset returns from the Center for Research in Securities Prices (CRSP) monthly stock file, which provides monthly prices; shares outstanding; dividends; and returns for available NYSE, AMEX, and NASDAQ stocks. We measure betas, $\widehat{\beta}_{i, t}$, for individual stocks using at least one and up to three years of monthly returns in a market-model OLS regression on a constant and the contemporaneous return on the value-weight NYSE-AMEX-NASDAQ portfolio. ${ }^{4}$ As we sometimes estimate beta using only twelve returns, we censor each firm's individual monthly return to the range (-50 percent,100 percent) in order to limit the influence of extreme firm-specific outliers. We use these stock-level estimates to form betasorted portfolios. The portfolios are value-weight and reformed each month using the most recent available betas. We consider sorts into 10, 20, and 40 portfolios. The results are not sensitive to the number of portfolios, and we thus concentrate on the 20-portfolio data set for most tests. These portfolio-return series span the 895 month period, 1927:06-2001:12.

Second, we estimate rolling betas on these 20 beta-sorted portfolios using a trailing window of 36 months. (We have replicated our results using 24 and 48 month beta-

\footnotetext{
${ }^{4}$ We skip those months in which a firm is missing returns. However, we require all observations to occur within a four-year window.
} 
estimation windows, and the results are robust to variation in window length.) We denote the time series of these rolling betas as the "post-formation betas" of the basis assets. These post-formation beta series span the 860 month period, 1930:052001:12.

At this stage of the analysis, it is important to verify that our stock-level beta estimates are actually useful and result in cross-sectional spread in the average postformation betas. We find that they are, as the average post-formation beta of the lowest beta portfolio is 0.63 while the post-formation beta of the highest beta portfolio is 1.77. However, the estimated post-formation betas for a particular portfolio are not constant through time. For the lowest beta portfolio, the post-formation beta varies from -0.35 to 1.92 , while the highest beta portfolio's post-formation beta varies from 0.59 to 3.63. Of course, most of this time-series variation in the post-formation betas is simply due to sampling variation.

Third, we form two portfolios from these 20 basis assets using Fama and Macbeth's [1973] cross-sectional regression technique. The purpose of this step is to directly control for the time-variation in post-formation betas documented above. Specifically, for each cross section, we regress the future excess return on the 20 basis assets on a constant and the portfolios' trailing-window post-formation beta. As shown by Fama and Macbeth [1973], the time series of these cross-sectional regression coefficients are excess returns on portfolios as well:

$$
\left[\begin{array}{c}
r_{\text {intercept }, t}^{e} \\
r_{\text {slope }, t}^{e}
\end{array}\right] \equiv\left(\left[\begin{array}{ll}
\underline{1} & \widehat{\beta}_{t-1}
\end{array}\right]^{\prime}\left[\begin{array}{ll}
\underline{1} & \widehat{\beta}_{t-1}
\end{array}\right]\right)^{-1}\left[\begin{array}{ll}
\underline{1} & \widehat{\beta}_{t-1}
\end{array}\right]^{\prime} \underline{r}_{t}^{e}
$$

Above, $\underline{1}$ is a vector of constants and $\widehat{\widehat{\beta}}_{t-1}$ a vector of post-formation betas of betasorted portfolios estimated using a trailing window that ends at $t-1$. $\underline{r}_{t}^{e}$ is the vector of excess returns on the beta-sorted portfolios.

We present the regression coefficients in matrix notation in equation (9) to highlight the fact that the cross-sectional regression coefficients are portfolios. As long as the trailing post-formation betas are accurate forecasts of future post-formation betas, the intercept portfolio return will be the excess return on a unit-investment zero-beta stock portfolio and the slope portfolio return will be the excess return on a unit-beta zero-investment portfolio. Furthermore, these portfolio strategies are implementable as long as the explanatory variables (i.e., the betas) are known in advance 
of the dependent variables (i.e., the basis-asset excess returns). The intercept and slope portfolio have average returns of 41 and 21 basis points per month respectively, though only the intercept portfolio's mean return is statistically significantly different from zero. These two excess-return series span the 859 month period, 1930:06-2001.

Though the steps taken so far are complicated, these complications are justified as they will produce two portfolio return series with relatively constant, preciselymeasured betas of zero and one for the intercept and slope portfolios respectively. This is desirable, as the time-series regressions in the next stage critically require that the portfolios we use have constant betas.

Fourth, we regress the intercept and slope portfolio's excess returns on a constant, the contemporaneous market excess return, and lagged inflation. As above, we use the value-weight NYSE-AMEX-NASDAQ portfolio as our proxy of the market portfolio. The excess return is computed by subtracting the three-month Treasury-bill rate from CRSP. Our measure of inflation is the series used by Campbell and Vuolteenaho [2004] in their study investigating aggregate market valuations and inflation. We first compute log growth rates on the producer price index. As these growth rates are very noisy especially in the first part of our sample, we smooth these log growth rates by taking an exponentially weighted moving average with a half life of 36 months (i.e., monthly decay to the power of 0.9806). Note that the exponentially-weighted moving averages use trailing inflation data, so there is no look-ahead bias in our smoothing. We also demean this inflation series using its full sample mean in order that the subsequent regression parameters are easier for the reader to interpret.

The two time-series regressions (10) are analogous to Black, Jensen, and Scholes [1972] and Gibbons, Ross, and Shanken [1989] time-series regressions with timevarying Jensen's [1968] alphas:

$$
\begin{aligned}
r_{\text {intercept }, t}^{e} & =a_{1}+b_{1} r_{M, t}^{e}+c_{1} \pi_{t-1}+u_{1, t} \\
r_{\text {slope }, t}^{e} & =a_{2}+b_{2} r_{M, t}^{e}+c_{2} \pi_{t-1}+u_{2, t}
\end{aligned}
$$

The empirical estimates of the two regression equations in (10) show that both portfolios have very precisely measured betas. Table 1 shows that for our preferred specification (20 beta-sorted portfolios where post-formation betas are estimated using a 36-month trailing window), the intercept portfolio has a beta of 0.0041 with a t-stat of 0.14 while the slope portfolio has a beta of 1.0205 with a t-stat of 34.38 . We also find that the conditional alpha of the intercept portfolio varies positively with lagged inflation as the estimate of $c_{1}$ is 1.50 with a t-statistic of 2.41. Our estimate of 
$c_{2}$ is reliably negative (value of -1.48 , t-stat of -2.35 ) indicating that inflation tracks the conditional alpha of the slope portfolio in an opposite fashion.

Because of our novel methodology, we now have identified two portfolios with relatively stable betas. If we could be confident that the trailing-window postformation beta estimates are perfect forecasts of the future basis-asset betas, the excess intercept and excess slope of the security market line would be given by $a_{1}+$ $c_{1} \pi_{t-1}$ and $a_{2}+c_{2} \pi_{t-1}$. In that hypothetical case, the time-series regression coefficients $b_{1}$ and $b_{2}$ would be exactly equal to zero and one. Despite the usefulness of our new approach, realistically speaking, the trailing-window betas we use as inputs of the Fama-MacBeth stage will never be perfect forecasts of future betas; there is no guarantee that $b_{1}=0$ and $b_{2}=1$ exactly. Since the point estimates are always close for the basis assets we consider, our method is informative enough to allow us to simply modify the formulas for the conditional excess intercept and excess slope of the security market line to take these small deviations into account.

As we can confidently reject the hypotheses that $b_{2}=0$ and $b_{2}=b_{1}$ for all sets of basis assets, straightforward algebra provides the alphas of a zero-beta and a unitbeta stock portfolio implied by the estimates of equation (10). The functions that map estimates of the parameters in regression (10) into the parameters of equation (8) are as follows. The excess slope of the security market line is

$$
\begin{aligned}
& g_{0}+g_{1} \pi_{t-1} \\
g_{0} \equiv & a_{2} / b_{2} \\
g_{1} \equiv & c_{2} / b_{2} .
\end{aligned}
$$

The excess intercept of the security market line is given by the function:

$$
\begin{aligned}
& h_{0}+h_{1} \pi_{t-1} \\
h_{0} \equiv & a_{1}-a_{2} b_{1} / b_{2} \\
h_{1} \equiv & c_{1}-c_{2} b_{1} / b_{2} .
\end{aligned}
$$

To summarize, these two formulas are the result of solving for the conditional alpha of a zero-beta and a unit-beta portfolio implied by estimates of system (10).

It is important to note that equations (11) and (12) also provide a correction for any potential measurement error problem caused by the use of estimated betas at the Fama-Macbeth stage. Even if betas are estimated with error in earlier stages, our final estimates of the excess slope and the excess intercept of the security market line are consistent. 
Table 2 reports the point estimates of the excess slope of the security market line. We focus on the specification using 20 portfolios and a 36-month beta-estimation window in the Fama-MacBeth stage, but as the table shows, the results are robust to small variations in these choices. Increasing the number of basis-asset portfolios in the tests typically strengthens our results.

We estimate $g_{0}$ as -0.0009 with a t-statistic of -0.40 and $h_{0}$ as 0.0008 with a tstatistic of 0.36. The interpretation of these near-zero intercept estimates is that when inflation is at its mean, the empirical beta slope and the zero-beta rate among stocks is consistent with the prediction of the Sharpe-Lintner CAPM. In other words, when inflation is at its time-series average, the Sharpe-Lintner CAPM "works." This is consistent with a form of money illusion in which people use historical average nominal growth rates to value the stock market, ignoring the current level of inflation which may be very different from inflation's historical average.

Our estimate for $g_{1}$ is -1.4487 with a t-statistic of -2.35 . As predicted by the Modigliani-Cohn hypothesis, the excess slope of the security market line comoves negatively with inflation. Our point estimates for the excess-intercept function are also consistent with the predictions of the theory: The estimate of $h_{1}$ is 1.5108 with a t-statistic of 2.40, which is statistically significantly different from zero but not from one. In words, we can reject the hypothesis that the market does not suffer from money illusion, but we cannot reject the hypothesis that inflation is (irrationally) fully priced into real stock yields. Furthermore, $g_{1}$ is economically and statistically very close to $-h_{1}$, as predicted. Finally, we can reject the joint hypothesis that both $g_{1}=0$ and $h_{1}=0$ against the two-sided alternative at the 5 percent level of significance.

\subsection{Alternative robustness checks}

We have also replicated our results with expanded sets of basis assets, presented in Table 3. The first panel uses 20 beta-sorted and 10 size-sorted portfolios as basis assets. The second panel uses 20 beta-sorted and 10 book-to-market-sorted portfolios as basis assets. The third and final panel uses 20 beta-sorted, 10 sizesorted, and 10 book-to-market-sorted portfolios as basis assets. The size-sorted and book-to-market-sorted portfolios are provided by Ken French on his web site at http:// mba.tuck.dartmouth.edu/ pages/ faculty/ ken.french/ data_library.html, which also documents the methods used to construct these portfolios. Adding these 
characteristics-sorted portfolios to the set of basis assets does not alter our basic conclusions, as the point estimates remain close to those obtained in the earlier tests. Thus we argue that our main conclusions are not sensitive to small changes in the set of basis assets.

In unreported tests, we also examine the Modigliani-Cohn hypothesis using longhorizon returns. We use the same portfolios as in our previous tests, except we hold the stocks for horizons ranging from three to sixty months. Our market return is also compounded in the same way, and then the compounded three-month Treasurybill interest rate is subtracted. Smoothed inflation is scaled to the same time units as the returns. Other than the change in the holding period, the test procedure is exactly the same as in the previous tests. We find point estimates consistent with the joint hypothesis of money illusion and the CAPM at the quarterly horizons and at horizons of three years and five years. However, for intermediate horizons (1224 months), any effect is small, with point estimates occasionally having the wrong sign. Though unfortunate, the low power and large standard errors of these longhorizon tests are at least partially to blame, as the Modigliani-Cohn hypothesis is never rejected statistically.

As part of our long-horizon tests, we also check to see whether our point estimates of the cross-sectional effect of money illusion are consistent with the aggregate mispricing of stocks versus bonds by Campbell and Vuolteenaho [2004]. In particular, we estimate a regression forecasting the excess market return with smoothed inflation, while controlling for the subjective risk-premium measure $\lambda^{S R C}$ of Polk, Thompson, and Vuolteenaho [2004]. As predicted by the Modigliani-Cohn hypothesis, the partial regression coefficient on inflation is positive, significant, and similar to our short-horizon cross-sectional estimate at all horizons.

Though we find evidence of Modigliani and Cohn's money illusion, our tests so far have only considered the Sharpe-Lintner version of the CAPM. However, it is theoretically possible that our results are simply due to an incorrect restriction on the intercept of the security market line implicit in that version of the CAPM.

Black [1973] considers the possibility that investors cannot borrow at the Treasurybill rate. If so, the likely effect of such inability to borrow is that the zero-beta rate among stocks deviates from the Treasury-bill rate. In other words, the Black CAPM allows the excess intercept and slope of the security market line to be non-zero. Therefore, an alternate explanation for our findings is that the spread between the true borrowing rate facing investors and the Treasury-bill rate comoves with inflation. 
Fortunately for our conclusions, data on actual borrowing rates indicates that the spread does not comove positively with inflation. Our three empirical proxies for the true borrowing rate are car-loan rates from commercial banks, personal-loan rates from commercial banks, and credit-card interest rates. We obtain these quarterly data from the Federal Reserve's web site. The data from commercial banks begins 1972:02, while the credit-card rate data begins 1994:11. We first compute the yield spread between these loans and maturity-matched Treasury yields. We then regress these spreads on smoothed inflation (in the same annualized units)

The regression results in Table 4 show that the yield spread between individuals' borrowing rates and Treasury rates comoves negatively, not positively, with lagged inflation. This result is not surprising, as Ausubel [1991] finds that credit-card interest rates appear "sticky" in responding to changes in market interest rates. Thus, we reject the Black CAPM as an alternative explanation for the observed time-variation in the excess slope of the security market line.

We also consider subjective risk premia determined in a world where multiple risk factors determine the cross-section of subjective expected returns. That is, we assume a world in which investors mistakenly mis-estimate real cash-flow growth of (and thus expected returns on) all stocks due to money illusion, but otherwise price stocks correctly in accordance with a multi-factor model. Furthermore, we assume that measured betas are not materially affected by this mispricing.

In our robustness checks below, we employ the well-known three-factor model of Fama and French [1993], but the below steps will easily generalize to any multifactor model for which the additional factors are expressed as long-short stock portfolios. The equations given above for the Sharpe-Lintner CAPM case, and therefore the regressions we will run to test the model and the Modigliani-Cohn hypothesis, easily generalize to this case. We begin by replacing equation (5) with the multifactor beta representation of assets' subjective risk premia:

$$
R_{i}^{e, S U B J}=\beta_{i} R_{M}^{e, S U B J}+\delta_{i}^{\prime} f .
$$

$f$ is a column vector of factor realizations for the given period and $\delta_{i}$ is a column vector of asset $i$ 's multiple-regression loadings on those factors. Here we assume that the factor-mimicking portfolios are long and short stocks in equal dollar amounts. Under these conditions there is no need for $S U B J$ superscripts, as the inflationrelated mispricing affects the yields of all stocks identically so that the expected 
return of any long-short stock portfolio is unaffected. Thus,

$$
\varepsilon_{i}=R_{i}^{e, O B J}-\beta_{i} R_{M}^{e, S U B J}-\delta_{i}^{\prime} f
$$

and therefore:

$$
\begin{aligned}
\varepsilon_{i} & =R_{i}^{e, O B J}-\beta_{i}\left[R_{M}^{e, O B J}-\delta_{i}^{\prime} f-\varepsilon_{M}\right] \Longleftrightarrow \\
\alpha_{i}^{O B J} & \equiv R_{i}^{e, O B J}-\beta_{i} R_{M}^{e, O B J}-\delta_{i}^{\prime} f=\varepsilon_{i}-\beta_{i} \varepsilon_{M} .
\end{aligned}
$$

$\alpha_{i}^{O B J}$ denotes the Jensen's alpha relative to the multifactor model, and is almost identical to the expression derived in the CAPM case, except that $\beta$ is a multifactor sensitivity on the market return:

$$
\alpha_{i}^{O B J}=\gamma_{0}+\gamma_{1} \pi-\beta_{i}\left(\gamma_{0}+\gamma_{1} \pi\right)
$$

In the Fama-MacBeth regressions, we now include as explanatory variables the estimated loadings on all three factors, including multifactor market betas. Let the additional non-market factor loadings be denoted by $\underline{\widehat{\delta}}_{t-1}$ where $\underline{\widehat{\delta}}_{t-1}$ has one row for each asset and one column for each non-market factor. The returns on the intercept and (all) slope portfolios are then given by:

$$
\left[\begin{array}{l}
r_{\text {intercept }, t}^{e} \\
r_{\text {allslopes }, t}^{e}
\end{array}\right] \equiv\left(\left[\begin{array}{lll}
\underline{1} & \widehat{\widehat{\beta}}_{t-1} & \widehat{\underline{\delta}}_{t-1}
\end{array}\right]^{\prime}\left[\begin{array}{lll}
\underline{1} & \widehat{\widehat{\beta}}_{t-1} & \underline{\widehat{\delta}}_{t-1}
\end{array}\right]\right)^{-1}\left[\begin{array}{lll}
\underline{1} & \widehat{\widehat{\beta}}_{t-1} & \underline{\hat{\delta}}_{t-1}
\end{array}\right]^{\prime} \underline{\underline{r}}_{t}^{e}
$$

$r_{\text {intercept }, t}^{e}$ represents the return (in excess of the riskless rate) on a portfolio anticipated to have zero loadings on all factors (including the market) and a unit net investment in stocks. $r_{\text {slope, } t}^{e}$, which is defined as the first element of $r_{\text {allslopes }, t}^{e}$, is the return on a portfolio anticipated to have a unit market loading and a zero loadings on the other factors. The remaining elements of $r_{\text {allslopes, }}^{e}$, are returns on portfolios with unit loadings on the other factors; they are not used in our subsequent analysis.

The actual factor loadings of the $r_{\text {intercept, } t}^{e}$ and $r_{\text {slope,t }}^{e}$ portfolios are again reasonably close to their hypothetical values. We observe this by regressing the time series of returns on the factors, as well as on $\pi$, our inflation variable:

$$
\begin{aligned}
r_{\text {intercept }, t}^{e} & =a_{1}+b_{1} r_{M, t}^{e}+B_{1}^{\prime} f_{t}+c_{1} \pi_{t-1}+u_{1, t} \\
r_{\text {slope }, t}^{e} & =a_{2}+b_{2} r_{M, t}^{e}+B_{2}^{\prime} f_{t}+c_{2} \pi_{t-1}+u_{2, t} .
\end{aligned}
$$

$f_{t}$ is a vector of factor realizations at time $t . \quad B_{1}$ and $B_{2}$ are regression coefficients on the non-market factors. As above, in order to estimate the slope of the security market line we need to adjust the intercept and slope portfolios slightly to get portfolios 
that (in sample) actually have the necessary loadings. Again, the process of cleaning out any extraneous loadings on other factors conveniently leaves us with security market line equations that are virtually identical to those in the CAPM case (except that the $b_{1}$ and $b_{2}$ now come from the regression that includes the other factors (i.e., they are multifactor betas). The excess slope and excess intercept of the security market line are again given by equations (11) and (12).

Table 5 contains our estimates for the Fama and French [1993] multi-factor model, which contains two factors in addition to the market factor. The factor series are provided by Ken French on his web site at http:// mba.tuck.dartmouth.edu/ pages/ faculty/ ken.french/ data_library.html. The first is $S M B$, the difference between the return on small and big market-capitalization stocks. The second is $H M L$, the difference between the return on high and low book-to-market ratio stocks. In Table 5 , we find that the estimated $g_{1}$ is close to 1 , the estimated $h_{1}$ is close to -1 , and the two are close to equal in absolute value but opposite in sign, just as predicted by the Modigliani and Cohn hypothesis (and just as we found using the CAPM as the risk model). For our preferred specification (36 months in post-formation loading regressions, 20 test asset portfolios) we obtain point estimates of -1.28 for $g_{1}$ (tstatistic of -1.75) and 1.28 for $h_{1}$ (t-statistic of 1.71). The tests using the multifactor model have less power, but we can still reject at the 10 percent level the hypothesis that inflation plays no role in the determination of the cross-sectional beta premium. The results for other specifications are qualitatively similar, as can be seen in Table 5 .

\section{Future research}

Although this and other papers present comprehensive evidence on the effect of money illusion on expected stock returns, there are many other important ways in which money illusion may manifest itself. As a consequence, many fruitful opportunities for future research on the potential effects of money illusion exist.

First, how does unexpected inflation relate to unexpected stock returns? A large literature, beginning with Lintner (1975) and Fama and Schwert (1977), finds a negative relation between stock returns and inflation. Fama (1981), Fama and Gibbons (1982), and Geske and Roll (1983) explain this result by arguing that an increase (decrease) in real activity is expected to coincide with a decrease (increase) in infla- 
tion. Stock prices, being forward-looking, incorporate the cash-flow news associated with a change in inflation. Our paper takes a static approach to thinking about inflation, examining the price level of the market in different inflation environments. In a world in which investors have money illusion, unexpected inflation is likely to drive markets down, and to drive some stocks down more than others. Working out the effects of unexpected inflation on the money illusion market is an exercise left for future research. However, while we believe that studying unexpected inflation may shed additional light on the impact of money illusion on the stock market, these considerations are unlikely to provide an alternative explanation for our findings of return predictability.

Second, companies are often financed with nominal bonds, suggesting additional rich testable implications in the response of stock prices to unexpected inflation. In the absence of money illusion, the CAPM can be used to price the total assets of a firm or just the firm's equity. Assuming that betas are accurately estimated, changing firm betas should not lead to CAPM failures in a rational market. However, leverage effects could conceivably combine with money illusion and unexpected inflation to create anomalies in the market's response to unexpected inflation. As Modigliani and Cohn (1979) point out, when inflation unexpectedly increases, the equity value of firms that have large amounts of long-term nominal debt should increase, at least relative to a similar firm with short-term nominal debt or long-term real debt. The absence of such a reaction would be anomalous. French, Ruback, and Schwert [1983] and Ritter and Warr [2002] test this hypothesis, and find little evidence for such a relation, which is consistent with the Modigliani-Cohn hypothesis.

The possible correlation between beta and leverage due to the presence of longterm nominal debt in a firm's capital structure might affect our expected-return tests as well. It is possible that during our sample period, negative shocks to inflation tended to occur at times when inflation was high and positive shocks at times when inflation was low. In this case, we would observe ex-post relatively strong performance by high-leverage firms at low inflation times and ex-post weak performance by these firms when inflation is high. Furthermore, if high-leverage firms have high equity betas, this effect could generate empirical findings similar to ours. Comprehensively eliminating this possiblity would require currently unavailable long-term data on investor inflation expectations and company leverage ratios, and is thus left to future research.

Third, money illusion is most likely to occur in markets that are difficult to ar- 
bitrage and that contain a large number of financially unsophisticated participants. Based on these characteristics, money illusion might be predicted to have strong effects in the market for residential real estate. The market for residential real estate also has very large sums at stake, both at the level of the individual consumer and in the aggregate, making it a particularly interesting market to study. Analogous to our observations in financial markets, real estate prices would be expected to become too high (relative to expected future rents) when nominal interest rates are low, and too low when nominal interest rates are high, regardless of the real interest rates at those times. Of course, it is the real rate that is important in the decision between renting and purchasing a home, at least if one makes the plausible assumption that rents rise with inflation. In our ongoing research, we are testing to see whether money illusion appears to be a feature of the real estate market.

We know of no paper that tests for money illusion as such in real estate prices. However, there is a literature that looks at the relation between inflation (especially shocks to inflation) and real estate prices. Two such papers are by Chan, Hendershott and Sanders (1990) and Liu, Hartzell and Hoesh (1997), who find that real values of real-estate investments respond negatively to inflation, at least in the short run.

Fourth, the United States has experienced a relatively small number of high- and low-inflation cycles in the past hundred years. Consequently, any test based on inflation levels is likely to suffer from relatively low statistical power. One obvious solution to this problem essentially provides more data by examining international markets as well, because many international markets have experienced many more periods of unusually high or low inflation. Cohn and Lessard (1980) tested the Modigliani-Cohn hypothesis using aggregate markets in a number of countries and found results consistent with the hypothesis. In a recent paper, Sellin (2001) reviews related evidence on the effects of money and inflation on stock prices.

Besides using international markets as an additional source of variation in inflation with which to test our main hypotheses, we can also develop additional cross-sectional hypotheses about the differences between international markets. For example, we might predict that in countries that have experienced exceedingly high and volatile inflation, people will be unlikely to suffer from money illusion when valuing stocks since inflation is so central a part of daily life and commerce.

Fifth, economists have long maintained that investor welfare could be improved if governments were to issue real rather than nominal bonds. Such "inflation-indexed" bonds have existed for some time in the United Kingdom and other countries, and 
in the last decade have come into existence in the United States as well. In our model, and in the thinking that underlies our analysis, we focus on investors choosing between stocks and nominal bonds. An area for future research is the introduction of inflation-indexed bonds and the impact that the existence of these bonds have on investors who would otherwise suffer from money illusion. Would the existence of such bonds in the market affect equilibrium prices of stocks in a way that either mitigates or exacerbates the effects observed here? Is it possible that the presence of such bonds in the market would serve to remind investors of the importance of inflation and in some way reduce money illusion generally? We plan to examine these questions in future work.

\section{Conclusions}

Do people suffer from money illusion when the stakes are high and the consequences of their decisions are significant? While we may disagree on the answer to this question, its importance is indisputable. If people suffer from money illusion, it is likely that this bias will be most important in valuing long-term contracts. Many important decisions, such as choosing between buying and renting a home or allocating one's portfolio between stocks and nominal bonds, depend critically on the decision-maker's ability to distinguish between nominal and real quantities.

Modigliani and Cohn [1979] suggest that stock-market investors suffer from money illusion. With trillions of dollars at stake, the stock and bond markets are among the most important markets for long-term contracts. Previous time-series studies have found that high inflation coincides with low prices for stocks relative to bonds. This relation may be caused by money illusion; however, as noted by Campbell and Vuolteenaho [2004], it may also be caused by the real discount rates used by investors being positively correlated with inflation.

We present novel cross-sectional evidence supporting Modigliani and Cohn's hypothesis that the market does in fact suffer from money illusion. Simultaneously examining the future returns of Treasury bills, safe stocks, and risky stocks allows us to distinguish money illusion from any change in the attitudes of investors towards risk. The key insight underlying our tests is that money illusion will have a symmetric effect on all stocks' future returns, regardless of their exposure to systematic risk. This constant effect is in contrast to the impact of investor risk attitudes on future 
stock returns, which is proportional to the stock's risk, as risky stocks' future returns will be affected much more than safe stocks' future returns. This insight allows us to cleanly separate the two competing effects.

Our empirical tests support the Modigliani-Cohn money-illusion hypothesis. When inflation is high, a stock provides higher than justified future returns relative to shortterm bonds, irrespective of the riskiness of the particular stock. This constant effect across stocks varies approximately one-for-one with the rate of inflation.

A critical assumption in our tests is that investors use the Sharpe-Lintner capital asset pricing model (CAPM) to evaluate the risk of a stock. Our cross-sectional tests leverage this Sharpe-Lintner CAPM assumption by noting that any effect of risk attitudes on a stock's price would have to result in an expected-return effect that is proportional to the stock's CAPM beta. As a consequence, our findings could be due to investors caring about some other risk than CAPM beta. We alleviate this concern by finding support for the money-illusion hypothesis using an alternative multi-factor model of risk. Nevertheless, one may never completely rule out the possibility of our results being due to a misspecified model of risk.

In addition to showing that stock-market investors suffer from money illusion, our results offer a partial explanation for the Sharpe-Lintner CAPM's poor empirical performance in recent samples. In an influential paper, Fama and French [1992] fail to find support for "the central prediction of [the CAPM], that average returns are positively related to market [betas]." Curiously, this negative results is primarily driven by their 1951-1960 and 1981-1990 subsamples. In the beginning of both subsamples inflation was very high. The cross-sectional implication of the Modigliani-Cohn hypothesis is that those are precisely the times when the slope of expected returns on beta observed in the data should be much lower than the equity premium. In a sense, money illusion may have killed the Sharpe-Lintner CAPM in those subsamples.

Although we do not explicitly consider money illusion's effect on investor welfare, we believe that our results nevertheless have some policy implications, however speculative. First, if investors suffer from money illusion, stable and low inflation is likely to result in a less mispriced stock market than volatile and high inflation. To the extent that real investment decisions are influenced by stock-market valuations, one would expect less stock market mispricing to be beneficial to the economy in the long run. Not only will market prices be more informative about investment opportunities, but also any catering (through a firm's choice of business investment) to 
mispricing that occurs because managers have short horizons will be reduced. ${ }^{5}$ Second, if government borrowing shifts from nominal bonds to inflation-indexed or real bonds, it is possible that the stock market will value stocks relative to real (instead of nominal) bonds, eliminating the effect of money illusion on stock prices. Third, and most importantly, to the extent that investors perceive a benefit from valuing stocks using nominal quantities, they should pay more attention to inflation when forecasting future nominal cash-flows.

\section{Appendix}

In this appendix, we present a stylized model of market equilibrium, where some investors suffer from money illusion and others do not. The model gives a simple prediction: The difference between the equity premium and the cross-sectional beta premium (i.e., the slope of the security market line) is equal to $c \pi /(1+\pi)$, where $\pi$ is the rate of inflation and $c$ is a measure of the risk-bearing capacity of money-illusioned investors relative to that of rational investors. On the one hand, as expected, if money-illusioned investors have all of the risk-bearing capacity in the economy, inflation translates almost one-for-one into the excess slope of the security market line. On the other hand, also as expected, if rational investors have all of the risk-bearing capacity, then the Sharpe-Lintner CAPM holds. For intermediate cases, the excess slope of the security-market line depends linearly on the share of risk-bearing capacity of the two investor groups.

The model has two periods, denoted by 0 and 1 . At time 0 , the investors trade but do not consume. At time 1, investors consume the payoffs from their portfolios, and there is no trading.

There are three traded assets, one nominal bond (asset indexed 1) in zero net supply and two stocks (assets indexed 2 and 3) both with one share outstanding. Price of these assets at time 0 are $p_{1}, p_{2}$, and $p_{3}$. Because we have no consumption

\footnotetext{
${ }^{5}$ Dow and Gorton [1997] model the connection between stock market efficiency and economic efficiency. Shleifer and Vishny [1990] study the importance of managers and firms having short horizons. Stein [1996] focuses on the link between market inefficiency and firm's real investment policies, modeling how an inefficient capital market can result in managers catering to market mispricing. Polk and Sapienza [2004] document catering effects in firm's capital expenditures related to mispricing.
} 
at time 0 , asset prices have meaning only in relative terms. We set $p_{1}=1$ as an arbitrary normalization, interpreting all relative to the nominal bond's price.

The asset payoffs are as follows. The nominal debt has no default risk. The rate of inflation, $\pi$, is known, and the nominal debt is thus risk-free in real terms as well. The real payoff to the debt is $X_{1}=F /(1+\pi)$, where $\mathrm{F}$ is the nominal face value of the bond. Set $F=1$ without any loss of generality, and thus the real debt payoff is $X_{1}=1 /(1+\pi)$.

The second asset is the stock of a relatively safe company and the third asset is a relatively risky company's stock. The real payoffs to the second asset and the third asset are $\widetilde{X}_{2}$ and $\widetilde{X}_{3}$. For simplicity, we make the expected payoffs for both assets equal, that is, $E\left(\widetilde{X}_{2}\right)=E\left(\widetilde{X}_{3}\right)=\bar{X}$. The uncertain future values of real assets are independent random variables with known variances $\operatorname{var}\left(\widetilde{X}_{2}\right)=\sigma^{2}$ and $\operatorname{var}\left(\widetilde{X}_{3}\right)=k \sigma^{2}, k>1$. In particular, these real payoffs do not depend on the rate of inflation $\pi$. The real payoff to the market portfolio of all assets is thus $\widetilde{X}_{2}+\widetilde{X}_{3}$ and the real return on the market portfolios is $\left(\widetilde{X}_{2}+\widetilde{X}_{3}\right) /\left(p_{2}+p_{3}\right)$. The nominal return on the market portfolios is $(1+\pi)\left(\widetilde{X}_{2}+\widetilde{X}_{3}\right) /\left(p_{2}+p_{3}\right)$.

Suppose two investors (or groups of investors), denoted by A and B, have meanvariance preferences over time 1 consumption and behave competitively as price takers. Initially, the assets are endowed evenly between the two groups of investors. Both investors maximize a mean-variance objective function, but in addition investor B suffers from money illusion.

Investor $\mathrm{A}$ has an absolute risk-bearing capacity of $(1-c), 0 \leq c \leq 1$. Investor A does not suffer from money illusion, perceives the above real payoffs correctly, and maximizes the mean-variance preference of time-1 consumption:

$$
\begin{aligned}
& w_{1} X_{1}+w_{2} E\left(\widetilde{X}_{2}\right)+w_{3} E\left(\widetilde{X}_{3}\right)-\frac{1}{2(1-c)} w_{2}^{2} \operatorname{var}\left(\widetilde{X}_{2}\right)-\frac{1}{2(1-c)} w_{3}^{2} \operatorname{var}\left(\widetilde{X}_{3}\right) \\
= & \frac{1}{(1+\pi)} w_{1}+\left(w_{2}+w_{3}\right) \bar{X}-\frac{1}{2(1-c)} w_{2}^{2} \sigma^{2}-\frac{1}{2(1-c)} w_{3}^{2} k \sigma^{2}
\end{aligned}
$$

subject to the budget constraint $.5\left(p_{2}+p_{3}\right)=w_{1}+p_{2} w_{2}+p_{3} w_{3}$ by choosing his portfolio allocations $w$. The first order conditions yield demand curves for risky 
assets:

$$
\begin{aligned}
& w_{2}=\frac{(1-c) \bar{X}}{\sigma^{2}}-\frac{(1-c)}{(1+\pi)} \frac{p_{2}}{\sigma^{2}} \\
& w_{3}=\frac{(1-c) \bar{X}}{k \sigma^{2}}-\frac{(1-c)}{(1+\pi)} \frac{p_{3}}{k \sigma^{2}}
\end{aligned}
$$

The idea that investor B suffers from money illusion manifests itself in two ways. First, investor B maximizes mean-variance preferences over nominal wealth. Second, investor B believes that the nominal growth in the value of corporate assets is a random variable with a distribution that does not depend on the rate of inflation. In other words, the investor B perceives nominal payoffs $X_{B 1}=F=1, \widetilde{X}_{B 2}=\widetilde{X}_{2}$, and $\widetilde{X}_{B 3}=\widetilde{X}_{3}$, irrespective of the inflation environment. We set the risk-bearing capacity of investor class B to $c$, which has the advantace of keeping the risk-bearing capacity of the economy as a whole constant as $c$ changes. Thus, investor B maximizes

$$
\begin{aligned}
& w_{B 1} X_{B 1}+w_{B 2} E\left(\widetilde{X}_{B 2}\right)+w_{B 3} E\left(\widetilde{X}_{B 3}\right)-\frac{1}{2 c} w_{B 2}^{2} \operatorname{var}\left(\widetilde{X}_{B 2}\right)-\frac{1}{2 c} w_{B 3}^{2} \operatorname{var}\left(\widetilde{X}_{B 3}\right) \\
= & w_{B 1}+\left(w_{B 2}+w_{B 3}\right) \bar{X}-\frac{1}{2 c} w_{B 2}^{2} \sigma^{2}-\frac{1}{2 c} w_{B 3}^{2} k \sigma^{2}
\end{aligned}
$$

subject to the budget constraint $.5\left(p_{2}+p_{3}\right)=w_{A 1}+p_{2} w_{A 2}+p_{3} w_{A 3}$ by choosing his portfolio allocations. The first order conditions yield demand curves for risky assets:

$$
\begin{aligned}
& w_{B 2}=\frac{c \bar{X}}{\sigma^{2}}-\frac{c p_{2}}{\sigma^{2}} \\
& w_{B 3}=\frac{c \bar{X}}{\sigma^{2}}-\frac{c p_{3}}{\sigma^{2}}
\end{aligned}
$$

In the equilibrium the asset market clears, and one share of both assets must be held by both investors:

$$
\begin{aligned}
1 & =w_{2}+w_{B 2}=\frac{\bar{X}}{\sigma^{2}}-\frac{(1+c \pi)}{(1+\pi)} \frac{p_{2}}{\sigma^{2}} \\
1 & =w_{3}+w_{B 3}=\frac{\bar{X}}{k \sigma^{2}}-\frac{(1+c \pi)}{(1+\pi)} \frac{p_{2}}{k \sigma^{2}}
\end{aligned}
$$


Solving for prices yields:

$$
\begin{aligned}
& p_{2}=\left[\frac{1+\pi}{1+c \pi}\right]\left[\bar{X}-\sigma^{2}\right] \\
& p_{3}=\left[\frac{1+\pi}{1+c \pi}\right]\left[\bar{X}-k \sigma^{2}\right]
\end{aligned}
$$

These prices makes sense: If money-illusioned investors dominate the market (i.e., $c=1$ ), then the price of a real asset in relation to the price of a nominal asset does not change with the rate of inflation.

The expected return premium of asset 3 over that of asset 2 is:

$$
\frac{E\left(\tilde{X}_{3}\right)}{p_{3}}-\frac{E\left(\widetilde{X}_{2}\right)}{p_{2}}=\left[\frac{1+c \pi}{1+\pi}\right]\left[\frac{\bar{X}}{\bar{X}-k \sigma^{2}}-\frac{\bar{X}}{\bar{X}-\sigma^{2}}\right]
$$

The return on the market portfolio is $\frac{\widetilde{X}_{2}+\widetilde{X}_{3}}{p_{2}+p_{3}}$, and the CAPM betas of the two stocks are

$$
\begin{aligned}
& \beta_{2}=\frac{\frac{2}{(1+k)} \bar{X}-\sigma^{2}}{\bar{X}-\sigma^{2}} \\
& \beta_{3}=\frac{\frac{2 k}{(1+k)} \bar{X}-k \sigma^{2}}{\bar{X}-k \sigma^{2}}
\end{aligned}
$$

The difference between the betas of the two assets is

$$
\beta_{3-2}=\frac{\left[\frac{2 k}{(1+k)} \bar{X}-k \sigma^{2}\right]\left[\bar{X}-\sigma^{2}\right]-\left[\bar{X}-k \sigma_{X}\right]\left[\frac{2}{(1+k)} \bar{X}-\sigma^{2}\right]}{\left[\bar{X}-k \sigma^{2}\right]\left[\bar{X}-\sigma^{2}\right]}
$$

The expected equity premium, or the expected return on the market portfolio less that on a risk-free asset, is

$$
\theta=\frac{E\left(\tilde{X}_{2}\right)+E\left(\tilde{X}_{3}\right)}{p_{2}+p_{3}}=\left[\frac{1+c \pi}{1+\pi}\right] \frac{2 \bar{X}}{\left[\bar{X}-\sigma^{2}\right]+\left[\bar{X}-k \sigma^{2}\right]}-\frac{1}{1+\pi}
$$

Finally, the slope of the security market line (the premium for one unit of beta exposure among stocks):

$$
\lambda=\left[\frac{1+c \pi}{1+\pi}\right] \frac{\left[\bar{X}-\sigma^{2}\right] \bar{X}-\left[\bar{X}-k \sigma^{2}\right] \bar{X}}{\left[\frac{2 k}{(1+k)} \bar{X}-k \sigma^{2}\right]\left[\bar{X}-\sigma^{2}\right]-\left[\bar{X}-k \sigma^{2}\right]\left[\frac{2}{(1+k)} \bar{X}-\sigma^{2}\right]}
$$


The difference between the beta premium and the equity premium simplifies to

$$
\left[\frac{1+c \pi}{1+\pi}\right]\left[\frac{\lambda}{\beta_{3-2}}-\theta\right]-\frac{1}{1+\pi}=\frac{-c \pi}{1+\pi}
$$

In words, the excess slope of the security market line $(-c \pi /(1+\pi))$ is determined by the product of inflation and the fraction of the market's risk-bearing capacity controlled by money-illusioned investors.

Harvard Business School

Kellogg Graduate School of Managment, Northwestern University

Harvard University and National Bureau of Economic Research 


\section{References}

Asness, Clifford, 2000, Stocks versus bonds: explaining the equity risk premium, Financial Analysts Journal 56(2), 96-113.

Asness, Clifford, 2003, Fight the Fed model: the relationship between future returns and stock and bond market yields, Journal of Portfolio Management, 30(1), $11-24$.

Ausubel, Lawrence M., 1991, The failure of competition in the credit card market, American Economic Review 81(1), 50-81.

Black, Fischer, Michael C. Jensen, and Myron Scholes, 1972, The capital asset pricing model: Some empirical tests, in Michael Jensen, ed.: Studies in the Theory of Capital Markets (Praeger, New York).

Campbell, John Y. and Tuomo Vuolteenaho, 2004, Inflation illusion and stock prices, American Economic Review Papers and Proceedings (forthcoming).

Chan, K.C, Patric H. Hendershott, and Anthony B. Sanders, 1990, Risk and Return on Real Estate: Evidence from Equity REITs, Real Estate Economics, 18(4), $431-452$.

Cohn, Richard and Donald Lessard, The effect of inflation on stock prices: international evidence, Unpublished Massachusetts Institute of Technology working paper.

Dow, James and Gary Gorton, 1997, Stock market efficiency and economic efficiency: Is there a connection?, Journal of Finance 52, 1087-1129.

Fama, Eugene F. and James D. MacBeth, 1973, Risk, return, and equilibrium: empirical tests, Journal of Political Economy 81, 607-636.

Fama, Eugene F., 1981, Stock returns, real activity, inflation, and money, American Economic Review 71(4), 545-65.

Fama, Eugene F. and Michael R. Gibbons, 1982, Inflation, real returns and capital investment, Journal of Monetary Economics, 9(3), 297-323.

Fama, Eugene F. and Kenneth R. French, 1992, The cross-section of expected stock returns, Journal of Finance 47, 427-467. 
Fisher, Irving. 1928. The Money Illusion. New York: Adelphi.

Fischer, Stanley and Franco Modigliani, 1978, Towards an understanding of the real effects and costs of inflation, Weltwirtschaftliches Archiv. 114(4), 810-833.

French, Kenneth R., Richard S. Ruback, and G. William Schwert, 1983, Effects of nominal contracting on stock returns, Journal of Political Economy 91(1), $70-96$.

Gibbons, Michael, Steven A. Ross, and Jay Shanken, 1989, A test of the efficiency of a given portfolio, Econometrica 99, 1121-1152.

Geske, Robert and Richard Roll, The fiscal and monetary linkage between stock returns and inflation, Journal of Finance 38, 1-33.

Gordon, Myron, 1962, The Investment, Financing, and Valuation of the Corporation (Irwin, Homewood, Ill.).

Gordon, Robert J., 1983, A century of evidence on wage and price stickiness in the United States, the United Kingdom, and Japan, in James Tobin ed.: Macroeconomics, Prices, and Quantities (Brookings Inst., Washington, D.C.)

Jensen, Michael C., 1968, The performance of mutual funds in the period 1945-1964, Journal of Finance 23(2), 389-416.

Lintner, John, 1965, The valuation of risk assets and the selection of risky investments in stock portfolios and capital budgets, Review of Economics and Statistics $47,13-37$.

Liu, Crocker H., David J. Hartzell, and Martin E. Hoesli, International evidence on real estate securities as an inflation hedge, Real Estate Economics, 25(2), 193-221.

Modigliani, Franco and Richard Cohn, 1979, Inflation, rational valuation, and the market, Financial Analysts Journal 35(3), 24-44.

Polk, Christopher and Paola Sapienza, 2004, The real effects of investor sentiment, Unpublished Northwestern University working paper

Polk, Christopher, Samuel Thompson, and Tuomo Vuolteenaho, 2004, Cross-sectional forecasts of the equity premium. Unpublished Harvard University working paper. 
Ritter, Jay R. and Richard S. Warr, 2002, The decline of inflation and the bull market of 1982-1999, Journal of Financial and Quantitative Analysis 37, 29-61.

Sellin, Peter, Monetary policy and the stock market, Journal of Economic Surveys 15(4), 491-541.

Shafir, Eldar, Peter A. Diamond, and Amos Tversky, 1997, On money illusion, Quarterly Journal of Economics 112, 341-74.

Sharpe, Steven A., 2002, Reexamining stock valuation and inflation: the implications of analysts' earnings forecasts, Review of Economics and Statistics 84(4), 632648 .

Sharpe, William, 1964, Capital asset prices: A theory of market equilibrium under conditions of risk, Journal of Finance 19(3) 425-442.

Shleifer, A. and R. Vishny, 1990, Equilibrium short horizons of investors and firms', American Economic Review Papers and Proceedings 80, 148-153.

Shleifer, Andrei and Robert W. Vishny, 1997, The limits of arbitrage, Journal of Finance 52(1), 35-55.

Stein, Jeremy, 1996, Rational capital budgeting in an irrational world, Journal of Business 69, 429-455.

Williams, John Burr, 1938, Evaluation by the rule of present worth, The Theory of Investment Value (Harvard University Press, Cambridge), 55-75. 
Table 1: Time-series regressions of intercept and slope portfolios The table shows OLS regressions of the intercept portfolio's $\left(r_{\text {intercept }, t}^{e}\right)$ and the slope portfolio's $\left(r_{\text {slope }, t}^{e}\right)$ excess return on a constant, contemporaneous excess market return $\left(r_{M, t}^{e}\right)$, and demeaned lagged inflation $\left(\pi_{t-1}\right)$.

$$
\begin{aligned}
r_{\text {intercept }, t}^{e} & =a_{1}+b_{1} r_{M, t}^{e}+c_{1} \pi_{t-1}+u_{1, t} \\
r_{\text {slope }, t}^{e} & =a_{2}+b_{2} r_{M, t}^{e}+c_{2} \pi_{t-1}+u_{2, t}
\end{aligned}
$$

The intercept and slope portfolios are constructed using Fama-Macbeth [1973] regressions of excess returns on $N$ beta sorted portfolios on a constant and the portfolios' lagged $K$-month post-formation betas. T-statistics are in parentheses. $R^{2}$ is adjusted for degrees of freedom. The regressions are estimated from the sample period 1930:06-2001:12, 859 monthly observations.

\begin{tabular}{cccccccccc}
$K$ & $N$ & $a_{1}$ & $a_{2}$ & $b_{1}$ & $b_{2}$ & $c_{1}$ & $c_{2}$ & $R_{\text {intercept }}^{2}$ & $R_{\text {slope }}^{2}$ \\
\hline \hline 36 & 20 & 0.0008 & -0.0009 & 0.0041 & 1.0205 & 1.5048 & -1.4784 & $0.44 \%$ & $58.03 \%$ \\
& & $(0.36)$ & $(-0.40)$ & $(0.14)$ & $(34.38)$ & $(2.41)$ & $(-2.35)$ & & \\
\hline 36 & 10 & 0.0008 & -0.0009 & -0.0344 & 1.0558 & 1.4588 & -1.4151 & $0.49 \%$ & $57.69 \%$ \\
& & $(0.33)$ & $(-0.40)$ & $(-1.12)$ & $(34.15)$ & $(2.23)$ & $(-2.16)$ & & \\
\hline 36 & 40 & 0.0007 & -0.0004 & 0.0575 & 0.9732 & 1.5099 & -1.5722 & $1.02 \%$ & $58.58 \%$ \\
& & $(0.33)$ & $(-0.21)$ & $(2.07)$ & $(34.75)$ & $(2.57)$ & $(-2.65)$ & & \\
\hline 24 & 20 & -0.0001 & -0.0001 & 0.0589 & 0.9641 & 1.6340 & -1.5561 & $1.12 \%$ & $57.19 \%$ \\
& & $(-0.06)$ & $(-0.03)$ & $(2.10)$ & $(34.02)$ & $(2.73)$ & $(-2.57)$ & & \\
\hline 48 & 20 & 0.0016 & -0.0017 & -0.0163 & 1.0394 & 1.2269 & -1.2224 & $0.22 \%$ & $57.23 \%$ \\
& & $(0.70)$ & $(-0.72)$ & $(-0.53)$ & $(33.55)$ & $(1.86)$ & $(-1.85)$ & & \\
\hline
\end{tabular}


Table 2: Excess intercept and slope of the security market

The table shows the estimated function that maps inflation into the excess slope and intercept of the security market line. First, we regress the intercept portfolio's $\left(r_{\text {intercept }, t}^{e}\right)$ and the slope portfolio's $\left(r_{\text {slope }, t}^{e}\right)$ excess return on a constant, contemporaneous excess market return $\left(r_{M, t}^{e}\right)$, and lagged inflation $\left(\pi_{t-1}\right)$.

$$
\begin{aligned}
r_{\text {intercept }, t}^{e} & =a_{1}+b_{1} r_{M, t}^{e}+c_{1} \pi_{t-1}+u_{1, t} \\
r_{\text {slope }, t}^{e} & =a_{2}+b_{2} r_{M, t}^{e}+c_{2} \pi_{t-1}+u_{2, t}
\end{aligned}
$$

The intercept and slope portfolios are constructed using Fama-Macbeth [1973] regressions of excess returns on $N$ beta sorted portfolios on a constant and the portfolios' lagged $K$-month post-formation betas. Second, we compute the functions that map the regression parameters to the excess slope and intercept of the security market line. The excess slope is defined as $g_{0}+g_{1} \pi_{t-1}$, where $g_{0} \equiv a_{2} / b_{2}$ and $g_{1} \equiv c_{2} / b_{2}$. The excess intercept is computed as $h_{0}+h_{1} \pi_{t-1}$, where $h_{0} \equiv a_{1}-a_{2} b_{1} / b_{2}$ and $h_{1} \equiv c_{1}-c_{2} b_{1} / b_{2}$. t-statistics computed using the delta method are in parentheses. We also report the test statistic and the two-sided p-values [in brackets] for the hypotheses that $\left[g_{1}, h_{1}\right]^{\prime}=[0,0]^{\prime}$ and $g_{1}+h_{1}=0$. The regressions are estimated from the sample period 1930:06-2001:12, 859 monthly observations.

\begin{tabular}{cccccccc}
$K$ & $N$ & $g_{0}$ & $g_{1}$ & $h_{0}$ & $h_{1}$ & {$\left[g_{1}, h_{1}\right]^{\prime}=\underline{0}$} & $g_{1}+h_{1}=0$ \\
\hline \hline 36 & 20 & -0.0009 & -1.4487 & 0.0008 & 1.5108 & 5.82 & 0.00 \\
& & $(-0.40)$ & $(-2.35)$ & $(0.36)$ & $(2.40)$ & {$[0.05]$} & {$[0.96]$} \\
\hline 36 & \multirow{2}{*}{10} & -0.0009 & -1.3403 & 0.0007 & 1.4126 & 5.20 & 0.00 \\
& & $(-0.40)$ & $(-2.16)$ & $(0.33)$ & $(2.23)$ & {$[0.07]$} & {$[0.95]$} \\
\hline 36 & \multirow{4}{*}{40} & -0.0004 & -1.6155 & 0.0007 & 1.6029 & 7.12 & 0.00 \\
& & $(-0.21)$ & $(-2.64)$ & $(0.32)$ & $(2.57)$ & {$[0.03]$} & {$[0.99]$} \\
\hline 24 & 20 & -0.0001 & -1.6140 & -0.0001 & 1.7290 & 8.37 & 0.01 \\
& & $(-0.06)$ & $(-2.56)$ & $(-0.05)$ & $(2.71)$ & {$[0.02]$} & {$[0.93]$} \\
\hline 48 & 20 & -0.0016 & -1.1761 & 0.0016 & 1.2077 & 3.46 & 0.00 \\
& & $(-0.72)$ & $(-1.85)$ & $(0.71)$ & $(1.86)$ & {$[0.18]$} & {$[0.98]$} \\
\hline
\end{tabular}


Table 3: Results from expanded asset sets

The table shows the estimated function that maps inflation into the excess slope and intercept of the security market line, estimated from expanded asset sets. First, we regress the intercept portfolio's $\left(r_{\text {intercept }, t}^{e}\right)$ and the slope portfolio's $\left(r_{\text {slope, },}^{e}\right)$ excess return on a constant, contemporaneous excess market return $\left(r_{M, t}^{e}\right)$, and lagged inflation $\left(\pi_{t-1}\right)$.

$$
\begin{aligned}
r_{\text {intercept }, t}^{e} & =a_{1}+b_{1} r_{M, t}^{e}+c_{1} \pi_{t-1}+u_{1, t} \\
r_{\text {slope }, t}^{e} & =a_{2}+b_{2} r_{M, t}^{e}+c_{2} \pi_{t-1}+u_{2, t}
\end{aligned}
$$

The intercept and slope portfolios are constructed using Fama-Macbeth [1973] regressions of excess returns on basis-asset portfolios on a constant and the portfolios' lagged $K$-month post-formation betas. Second, we compute the functions that map the regression parameters to the excess slope and intercept of the security market line. The excess slope is defined as $g_{0}+g_{1} \pi_{t-1}$, where $g_{0} \equiv a_{2} / b_{2}$ and $g_{1} \equiv c_{2} / b_{2}$. The excess intercept is computed as $h_{0}+h_{1} \pi_{t-1}$, where $h_{0} \equiv a_{1}-a_{2} b_{1} / b_{2}$ and $h_{1} \equiv c_{1}-c_{2} b_{1} / b_{2}$. t-statistics computed using the delta method are in parentheses. We also report the test statistic and the two-sided p-values [in brackets] for the hypotheses that $\left[g_{1}, h_{1}\right]^{\prime}=[0,0]^{\prime}$ and $g_{1}+h_{1}=0$. The regressions are estimated from the sample period 1930:06-2001:12, 859 monthly observations.

\begin{tabular}{ccccccc}
\hline \hline \multicolumn{7}{c}{ 20 beta-sorted and 10 ME-sorted portfolios } \\
\hline$K$ & $g_{0}$ & $g_{1}$ & $h_{0}$ & $h_{1}$ & {$\left[g_{1}, h_{1}\right]^{\prime}=\underline{0}$} & $g_{1}+h_{1}=0$ \\
\hline 36 & 0.0005 & -1.6660 & 0.0002 & 1.5911 & 6.94 & 0.00 \\
& $(0.22)$ & $(-2.55)$ & $(0.07)$ & $(2.41)$ & {$[0.03]$} & {$[0.95]$} \\
\hline \hline \multicolumn{7}{c}{20 beta-sorted and 10 BE/ME-sorted portfolios } \\
\hline$K$ & $g_{0}$ & $g_{1}$ & $h_{0}$ & $h_{1}$ & {$\left[g_{1}, h_{1}\right]^{\prime}=\underline{0}$} & $g_{1}+h_{1}=0$ \\
\hline 36 & 0.0001 & -1.9251 & -0.0000 & 2.0335 & 10.90 & 0.01 \\
& $(0.03)$ & $(-3.12)$ & $(-0.02)$ & $(3.23)$ & {$[0.00]$} & {$[0.93]$} \\
\hline \hline 20 & beta-sorted, 10 ME-sorted, and 10 BE/ME-sorted portfolios \\
\hline$K$ & $g_{0}$ & $g_{1}$ & $h_{0}$ & $h_{1}$ & {$\left[g_{1}, h_{1}\right]^{\prime}=\underline{0}$} & $g_{1}+h_{1}=0$ \\
\hline 36 & 0.0012 & -2.0503 & -0.0007 & 2.0644 & 9.86 & 0.00 \\
& $(0.52)$ & $(-3.13)$ & $(-0.30)$ & $(3.13)$ & {$[0.01]$} & {$[0.99]$} \\
\hline \hline
\end{tabular}


Table 4: Inflation and the spread between borrowing and Treasury rates The table regresses proxies for the spread between borrowing rates that individuals face and Treasury rates on lagged inflation. The inflation series $(\pi)$ is the smoothed inflation used in earlier tests, annualized by multiplying the series by 12 . The tstatistics are based on Newey-West standard errors computed using four lags and leads. The heading of each panel specifies the spread measure being used as the dependent variable. Data are quarterly.

48 month car loans from commerical banks, spread over the 48-month T-note yield

\begin{tabular}{cccccc}
\hline constant & (t-stat) & slope on $\pi$ & (t-stat) & Adj. $R^{2}$ & $N$ \\
\hline \hline 3.4327 & $(13.9)$ & -0.0489 & $(-0.9)$ & 0.01 & 124 \\
\hline
\end{tabular}

24 month personal loans from commerical banks spread over the 24-month T-note yield

\begin{tabular}{cccccc}
\hline constant & (t-stat) & slope on $\pi$ & (t-stat) & Adj. $R^{2}$ & $N$ \\
\hline \hline 9.2135 & $(29.4)$ & -0.5596 & $(-7.9)$ & 0.58 & 124 \\
\hline
\end{tabular}

Credit card accounts (interest rates), spread over the 90-day T-bill yield

\begin{tabular}{cccccc}
\hline constant & (t-stat) & slope on $\pi$ & (t-stat) & Adj. $R^{2}$ & $N$ \\
\hline \hline 11.4532 & $(22.8)$ & -0.4270 & $(-2.0)$ & 0.15 & 33 \\
\hline
\end{tabular}

Credit card accounts (assessed interest), spread over the 90-day T-bill yield

\begin{tabular}{cccccc}
\hline constant & (t-stat) & slope on $\pi$ & (t-stat) & Adj. $R^{2}$ & $N$ \\
\hline \hline 11.1719 & $(21.1)$ & -0.4547 & $(-2.0)$ & 0.12 & 33 \\
\hline
\end{tabular}


Table 5: Results for the Fama-French three-factor model

The table repeats the tests of Table 2 using the Fama-French [1993] three-factor model in place of the Sharpe-Lintner CAPM. First, we regress the excess returns on the basis-asset portfolios on a constant and the portfolios' lagged $K$-month post-formation factor loadings. The intercept portfolio's $\left(r_{\text {intercept }, t}^{e}\right)$ and the slope portfolio's $\left(r_{\text {slope }, t}^{e}\right)$ excess returns are the coefficient time series corresponding to the intercept and the three-factor model's market loading, respectively. Second, we regress these returns on a constant, contemporaneous factor returns, and lagged inflation $\left(\pi_{t-1}\right)$.

$$
\begin{aligned}
r_{\text {intercept }, t}^{e} & =a_{1}+b_{1,1} r_{M, t}^{e}+b_{1,2} r_{S M B, t}^{e}+b_{1,3} r_{H M L, t}^{e}+c_{1} \pi_{t-1}+u_{1, t} \\
r_{\text {slope }, t}^{e} & =a_{2}+b_{2,1} r_{M, t}^{e}+b_{2,2} r_{S M B, t}^{e}+b_{2,3} r_{H M L, t}^{e}+c_{2} \pi_{t-1}+u_{2, t}
\end{aligned}
$$

The excess slope is defined as $g_{0}+g_{1} \pi_{t-1}$, where $g_{0} \equiv a_{2} / b_{2,1}$ and $g_{1} \equiv c_{2} / b_{2,1}$. The excess intercept is defined as $h_{0}+h_{1} \pi_{t-1}$, where $h_{0} \equiv a_{1}-a_{2} b_{1,1} / b_{2,1}$ and $h_{1} \equiv$ $c_{1}-c_{2} b_{1,1} / b_{2,1}$. T-statistics computed using the delta method are in parentheses. We also report the test statistic and the two-sided p-values [in brackets] for the hypotheses that $\left[g_{1}, h_{1}\right]^{\prime}=[0,0]^{\prime}$ and $g_{1}+h_{1}=0$. The regressions are estimated from the sample

\begin{tabular}{|c|c|c|c|c|c|c|}
\hline \multicolumn{7}{|c|}{20 beta-sorted portfolios } \\
\hline $\bar{K}$ & $g_{0}$ & $g_{1}$ & $h_{0}$ & $h_{1}$ & {$\left[g_{1}, h_{1}\right]^{\prime}=\underline{0}$} & $g_{1}+h_{1}=$ \\
\hline 36 & 0.0003 & -1.2788 & -0.0003 & .2787 & 3.13 & 0.00 \\
\hline & & $(-1.7 !$ & $(-0.13$ & (1.71) & [0.21] & \\
\hline \multicolumn{7}{|c|}{20 beta-sorted and 10 ME-sorted portfolios } \\
\hline$K$ & $g_{0}$ & $g_{1}$ & $h_{0}$ & $h_{1}$ & {$\left[g_{1}, h_{1}\right]^{\prime}=\underline{0}$} & $g_{1}+h_{1}=$ \\
\hline 36 & & 0.99 & 0.001 & 1.0099 & 2.30 & \\
\hline & & $(-1.5$ & $(0.75$ & $(1.52)$ & [0.32] & \\
\hline \multicolumn{7}{|c|}{20 beta-sorted and $10 \mathrm{BE} / \mathrm{ME}$-sorted portfolios } \\
\hline$K$ & $g_{0}$ & $g_{1}$ & $h_{0}$ & $h_{1}$ & {$\left[g_{1}, h_{1}\right]^{\prime}=\underline{0}$} & $g_{1}+h_{1}=0$ \\
\hline \multirow[t]{2}{*}{36} & -0.0014 & -0.9099 & 0.0009 & 0.9615 & 2.28 & 0.00 \\
\hline & $(-0.40)$ & $(-3.12)$ & $(0.35)$ & $(1.36)$ & {$[0.32]$} & [0.99] \\
\hline \multicolumn{7}{|c|}{20 beta-sorted, 10 ME-sorted, and $10 \mathrm{BE} / \mathrm{ME}$-sorted portfolios } \\
\hline $\bar{K}$ & $g_{0}$ & $g_{1}$ & $h_{0}$ & $h_{1}$ & {$\left[g_{1}, h_{1}\right]^{\prime}=\underline{0}$} & $g_{1}+h_{1}=0$ \\
\hline \multirow[t]{2}{*}{36} & -0.00 & -1.1630 & 0.0012 & 1.1950 & 3.54 & 0.00 \\
\hline & $(-0.62)$ & $(-1.80)$ & $(0.60)$ & $(1.84)$ & [0.17] & [0.98] \\
\hline
\end{tabular}
period 1930:06-2001:12, 859 monthly observations. 
$-7.4 \%<=$ inflation $<0.99 \%$

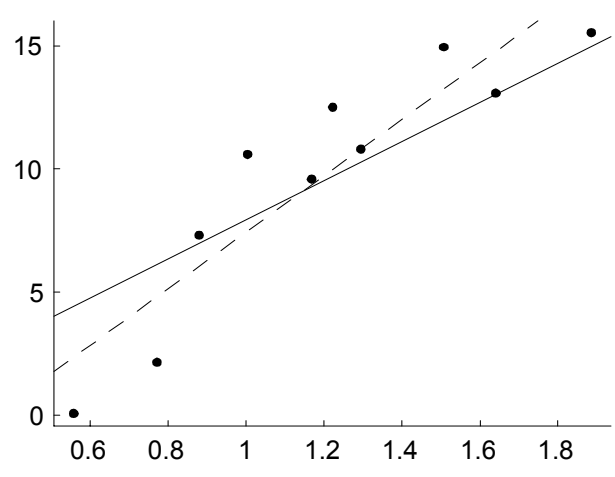

$2.3 \%<=$ inflation $<4.3 \%$

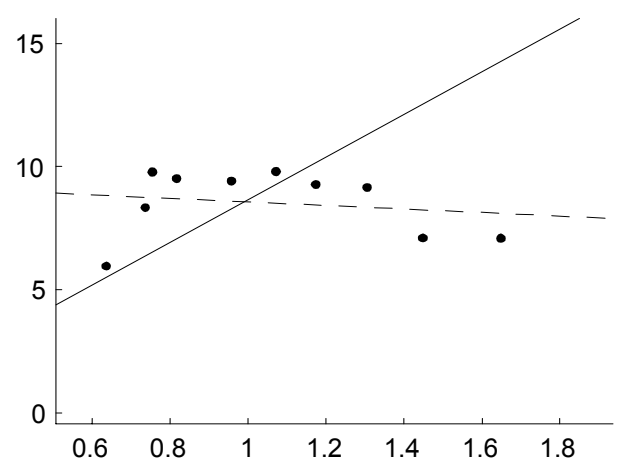

$1 \%<=$ inflation $<2.3 \%$

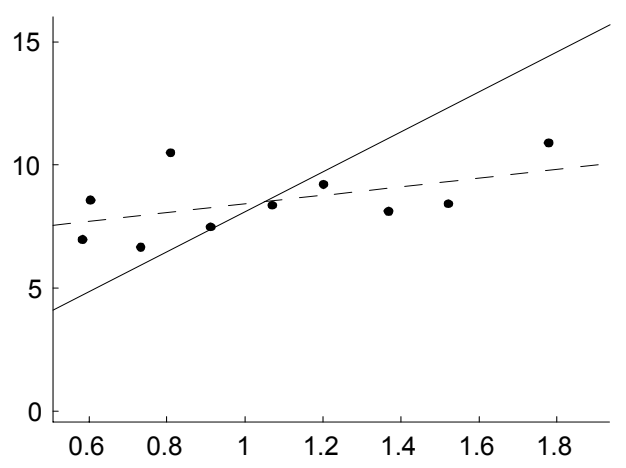

$4.4 \%<=$ inflation $<9.3 \%$

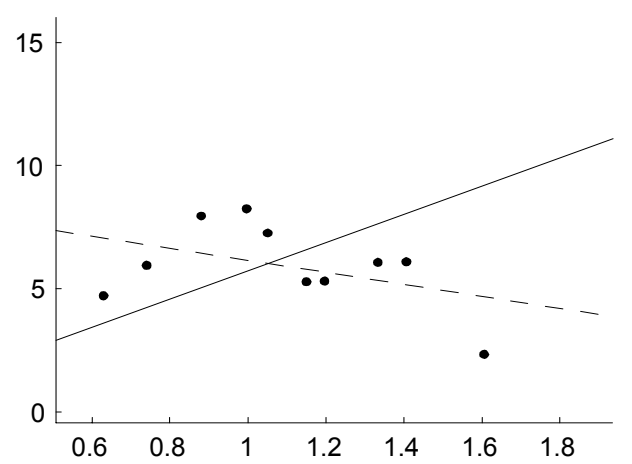

Figure 1: The empirical relation between average excess returns and beta in different inflation environments.

We first create ten portfolio by sorting stocks on their past estimated betas. We then record the excess returns on these portfolios. Next, we sort months in our 1927:06-2001:12 sample into four groups based on lagged inflation (defined as the smoothed change in the producer price index). For each group, we then estimate the post-formation betas and average excess returns. The average annualized excess returns (y-axis) and betas (x-axis) of these portfolios form the graphs. The solid line (drawn from the $[0,0]$ to $[1$, average market's excess return in this subsample]) is the relation predicted by the Sharpe-Lintner CAPM. The dashed line is the fitted line computed by regressing the average returns on betas in each subsample. 